\title{
CR Research Square \\ Application of Fusion-Fluorescence Imaging Using Indocyanine Green in Endoscopic Endonasal Surgery: Preliminary Data
}

Min Ho Lee ( $\nabla$ minho919.lee@catholic.ac.kr)

Uijeongbu St. Mary's Hospital https://orcid.org/0000-0001-6174-7579

Tae-Kyu Lee

Uijeongbu St Mary's Hospital

\section{Research Article}

Keywords: pituitary adenoma, endoscope, indocyanine green, fluorescence

Posted Date: June 8th, 2021

DOl: https://doi.org/10.21203/rs.3.rs-564174/v1

License: (c) (1) This work is licensed under a Creative Commons Attribution 4.0 International License.

Read Full License 


\section{Abstract}

\section{Purpose}

Indocyanine green (ICG) has been used in endoscopic surgery in the neurosurgical field, but it has been challenging to determine the associated efficiency due to limitations with visualization in the previous endoscopic system. A new endoscopic system was recently introduced; therefore, we summarize our experiences with the application and integration of the system.

\section{Methods}

From March to May 2021, a newly introduced endoscopic system was used in 6 patients. (3 pituitary adenomas, 1 pituitary apoplexy, 2 tuberculum sellae meningiomas) and $12.5 \mathrm{mg}$ of ICG was injected for each study.

\section{Results}

Three pituitary adenomas, including one acromegaly, were well identified with ICG. However, one pituitary apoplexy and two meningiomas were not visualized with ICG. Meanwhile, ICG appeared to be effective for determining the viability of nasoseptal mucosa.

\section{Conclusion}

ICG provides real-time information during endoscopic endonasal surgery. We suggest that the pituitary adenoma can be stained with an ICG using the fusion-fluorescence imaging endoscopic system. This approach will enhance the surgeon's ability to achieve gross total resection.

\section{Introduction}

Indocyanine green (ICG) angiography has become a well-established technology in several surgical fields, starting from ophthalmology and it has extended to abdominal surgery.[1-5] In the neurosurgical surgery field, microscopic ICG angiography was first adopted in vascular surgery by Rabbe, in 2003.[6] Currently, ICG angiography is widely used and it provides real-time information about the patency of vessels and surrounding small perforators during an aneurysm surgery. $[7,8]$ The approach also provides a reliable intraoperative assessment of bypass patency, during anastomosis surgery. $[9,10]$

ICG was initially used in endoscopic surgery in the neurosurgical field, but it was difficult to achieve sufficient efficiency due to visualization limitations in the previous endoscopic system. However, a new endoscopic system was introduced and implemented at our hospital and we would like to share initial experiences with applying the new approach.

\section{Material And Methods}


The operations performed with the new endoscopic system were organized retrospectively. The study protocol was reviewed and approved by the Institutional Review Board (IRB), and adhered to the recommendations of the Declaration of Helsinki for biomedical research involving human subjects (1975). The informed consent was waived by the IRB.

From March to May 2021, cases of endoscopic endonasal surgery using ICG were collected retrospectively. Six consecutive cases were enrolled in the study. Four cases were pituitary adenoma. The other two cases were tuberculum sellae meningiomas.

\section{Surgical techniques}

The surgical procedure was similar with previously reported techniques.[11-13] The patient's head was held in place with May-field 3-pointed pin fixation, and neuronavigational system was used. Surgery was performed with binostril endoscopic transsphenoidal approach in all patients. During the surgery for pituitary adenoma, the surgeon first performed piecemeal resection of the tumor mass to relieve the compressed normal gland. All lesions suspected to be tumors showing uptake by ICG were removed. The pseudocapsule was left in place to avoid potential iatrogenic injury to the gland. After removal of the tumor, minimal cauterization using bipolar cautery was performed over the normal gland. The surgery for tuberculum sellae meningioma, nasoseptal flap was prepared at the nasal stage. After the tumor was removed, the artificial dura was laid down with a bilayer (inlay and onlay) button. It was placed intradurally as an inlay graft and extradurally as an onlay graft. Finally, the harvested nasoseptal flap was rotated into position to reconstruct the skull base defect. Postoperative lumbar drainage was performed for 5 days.

\section{Florescence imaging system}

Fusion ICG fluorescence images were obtained using the Stryker 1688 AIM endoscopic system, a complementary metal-oxide semiconductor camera head, and a near-infrared laser diode for ICG excitation at a wavelength of $805 \mathrm{~nm}$. This system provides monochromatic fluorescence images under near-infrared light illumination, color images under white-light illumination, and fusion images made up of pseudo-color (green) fluorescence images and white-light color images (fusion ICG- fluorescence images). All these images were displayed in the monitor simultaneously.[14] A standard dose of $12.5 \mathrm{mg}$ of ICG in $10 \mathrm{ml}$ of aqueous solution within $1 \mathrm{~min}$ of peripheral bolus injection. The timing of injection of ICG is different for each case. It is described in the result session separately.

\section{Results}

\section{Tumor ICG uptake}

Endoscopic tumor removal was performed in three patients with pituitary adenomas including two nonfunctioning pituitary adenomas, and one growth-hormone releasing pituitary adenoma. Tumor staining was confirmed in all three cases. Meanwhile, ICG uptake was not observed in two patients with 
tuberculum sellae meningioma and one pituitary apoplexy. Three cases that showed ICG uptake are described in detail, below (Table 1).

\section{Case 1}

A 49-year-old female patient visited the out-patient department, presenting with refractory headache that had persisted for 5 months. On MRI, the $15 \mathrm{~mm}$-sized tumor had suprasellar extension behind the normal gland. The patient did not exhibit visual symptoms or hormone dysfunction, but due to the refractory headache, she indicated that she wanted to receive treatment and agreed to undergo surgery. A standard endoscopic endonasal trans-sphenoidal approach was determined to be optimal for the patient. At the start of the surgery, $12.5 \mathrm{mg}$ of ICG was injected. The sellar floor was reached 30 minutes after the injection and the tumor was identified after the dura was opened. The boundary between the normal gland and the tumor was identified with a neuro-navigation system, and the margin was clearly confirmed on the ICG scope image. The pathologist's report indicated pituitary adenoma for the frozen biopsy specimens, with high ICG uptake. The tumor was sufficiently removed, and all residual tumors with ICG uptake were also removed. A gross total resection was confirmed in the post-operative image, and the patient was discharged without any complications.

\section{Case 2}

A 78-year-old female patient visited the out-patient department with bitemporal hemianopsia. MRI indicated that the $25 \mathrm{~mm}$-sized tumor was compressed and the optic chiasm was displaced. To determine the tumor's ICG uptake time, $12.5 \mathrm{mg}$ of ICG was injected before opening the dura. Afterwards, the ICG uptake of the tumor was confirmed based on the elapsed time. The nasal septum and mucosa of the turbinate all showed uptake within 30 seconds, but the tumor was visualized with ICG after 20 minutes. Thirty minutes after the ICG injection, the tumor showed a high overall uptake. The tumor was removed piecemeal using a ring curette. All residual tumors that showed ICG uptake were removed. A gross total resection was confirmed in the post-operative image, and the patient was discharged without any complications.

\section{Case 3}

A 28-year-old male patient visit the out-patient department, presenting with visual disturbance, and bitemporal hemianopsia. The patient had acromegalic features, with an enlarged face, protruding lower jaw, and a larger nose. Basal hormone assay indicated that the patient had acromegaly $(\mathrm{GH}: 51.23 \mathrm{ng} / \mathrm{ml}$, IGF-1: $691.0 \mathrm{ng} / \mathrm{ml}$ ) and a $25 \mathrm{~mm}$ pituitary adenoma with a suprasellar extension was diagnosed by MRI. A standard endoscopic endonasal trans-sphenoidal approach was determined as the best treatment approach. At the start of the surgery, $12.5 \mathrm{mg}$ of ICG was injected. The tumor was exposed 40 minutes after ICG was injected. The tumor showed ICG uptake that was less than the previous nonfunctioning pituitary adenoma. The tumor was removed with a ring curette. A gross total resection was confirmed in the post-operative image. 
One of the cases in this study, a patient with pituitary apoplexy, visited the emergency department with complaints of a sudden bursting headache. The MRI showed a hemorrhagic cyst at the sellar region. ICG was injected as indicated by the aforementioned protocol. The ICG took 30 minutes to reach the tumor, but there was no uptake of ICG in the tumor tissue. Two cases with tuberculum sellae meningiomas also presented with visual disturbance. For both cases, the ICG was injected, as indicated above and required 50 and 60 minutes respectively, to reach the tumor, but there was no uptake of ICG in the tumor tissue.

\section{Nasoseptal flap preparation}

We used ICG to assess nasoseptal mucosa conditions. The exact pathway of the vessel could not be confirmed through ICG, but the mucosal condition could be predicted with ICG staining. Healthy mucosa showed good ICG uptake through the entire mucosa, for example, the patient in Case 3 (Figure 4A). The ICG was also checked to confirm the viability of nasoseptal mucosa in a patient with tuberculum sellae meningioma. The patient had a previous history of septoplasty and the septal mucosa was not problematic based on the white light view, but the viability of mucosa was poor based on an ICG window, in which the mucosa showed less uptake of ICG than healthy mucosa. Therefore, reconstruction was performed by making flaps with the mucosa of the floor instead, which showed better uptake of ICG than septal mucosa (Figure 4B).

\section{Discussion}

The newly introduced endoscopic system can is a helpful approach for endonasal endoscopic surgery, because it allows good visualization of the pituitary adenoma, and viability confirmation of the mucosa.

The emission and the absorption spectra of ICG make it useful in endoscopic surgery. The peak emission and absorption of ICG is in a range of $800-850 \mathrm{~nm}$. ICG has already been used in many fields and has been applied in various approaches. In the field of neurosurgery, it was used to check re-filling after aneurysm clipping, or to check vessel patency after anastomosis surgery. It has also been used to identify feeding arteries and draining veins in hyper-vascular lesions such as arteriovenous malformations or hemangioblastomas. $[15,16]$ The effect was sufficiently proven in vascular surgery, but there have been concerns about using ICG in tumor staining. In glioma surgery, the use of 5-aminolevulinic acid increased the gross total resection rate and improved survival.[17] However, in pituitary surgery, the effectiveness of 5-aminolevulinic acid was very limited.[18-20] Previously, there have been many efforts to stain the pituitary adenoma using ICG.[21-23] However, in previous endoscopic systems, the ICG was detected using xenon as a light source. ICG has an excitation range from $800-850 \mathrm{~nm}$, however, the effective detection range of filtered xenon is $845-870 \mathrm{~nm}$. Therefore, xenon had low excitation for ICG and only a very dark and blurry images were obtained which limited the applications for ICG in surgery. Recently, Chang et al.[24] published a review article on the use of optical fluorescence agents during pituitary adenoma surgeries and indicated that ICG and folate receptors could be used clinically to differentiate pituitary adenomas from normal tissue, which aligns with the results of our study. Some papers have reported that tumor staining with ICG is possible.[21, 25] However, other papers reported that tumor 
staining with ICG was difficult and the clinical effects could only be obtained by uptake of other structures around the tumor.[22, 23, 26-28] Lee et al. introduced the second-window ICG method as a new ICG approach to overcome these limitations.[29] They used a folate analog conjugated to a near-infrared fluorescent dye (OTL38). Patients were infused with OTL38 2-4 hours prior to surgery. They reported that this approach was highly specific for nonfunctioning adenomas did not have utility in functioning adenomas.[30] Lee et al. assessed a study group and used ICG for various intracranial tumors, which showed impressive results.[31] However, this method was problematic due the timing for injecting a high dose of ICG which should be injected 24 hours before operation. Although ICG is a relatively safe drug with few side effects, using high doses is bound to be a burden for patients and clinicians. The endoscopic system in the present study used low-dose ICG, which is very convenient and can be used just before or during the surgery. Previously, this fusion-fluorescence imaging system that used ICG was applied in laparoscopic surgery. In these studies, tumors, such as hepatomas, were well visualized.[14, 32, 33] For cases of meningioma, reports have indicated that the uptake is can be confirmed using the second window ICG method mentioned above, which is in agreement with our study results and observations.[30] However, other papers have not yet reported on uptake for meningioma.[16, 22, 34] With the study design, it was not possible to confirm whether the uptake was due to the tumor characteristics or the endoscopic system or the difference in the ICG injection protocol. In this study, GH-releasing pituitary adenoma showed weaker ICG uptake compared to other nonfunctioning pituitary adenomas. It is hypothesized that this occurs due to the difference in angiogenesis between tumor types as angiogenesis is essential for tumor growth. In contrast to other tumors, pituitary adenomas are less vascular than the normal pituitary gland. There is also a difference in angiogenesis between functioning pituitary adenomas and non-functioning pituitary adenomas.[35]

Pituitary adenomas exhibit relatively high long-term recurrence rates and delayed intervention is often required. The overall risk of recurrence after pituitary tumor surgery is reported to be between $7-33 \%$ at 510 years.[36-40] 0'Sullivan et al.[41] reported a recurrence rate of $0 \%$ in the gross total resection group. In comparison, based on the presence of intrasellar and extrasellar remnants, the recurrence rates after 5 years were reported as $15.4 \%$ and $51.4 \%$, respectively. Therefore, if tumor staining becomes clearer using ICG, it is expected that the recurrence rate can be reduced.

A nasoseptal flap is a surgical technique that is applied in skull base reconstruction following anterior skull base tumor removal. Knowledge of the anatomical variations of the sphenopalatine artery and the surrounding structures is crucial when preparing nasoseptal flaps. Because of its specific septal branch blood supply, the nasoseptal flap provides reliable revascularization and robust coverage for skull base reconstruction.[42] It is difficult to find the exact run of the artery when preparing nasoseptal flaps.

However, it would be very helpful if the approximate run of the artery could be estimated. As in this study, it is expected that ICG can be applied to overcome the limitations of what can be visualized in white light and applied as an improved tool for more complete surgery.

\section{Limitations}


This study is a preliminary result and the number of cases is very small. Therefore, it will be necessary to build a proper usage protocol with more experience and additional studies and observations.

\section{Conclusion}

ICG provides real-time information during endoscopic endonasal surgery. We suggest that the pituitary adenoma can be stained with ICG using the fusion-fluorescence imaging endoscopic system. This approach will enhance the surgeon's ability to achieve gross total resection and improve patient outcomes.

\section{Declarations}

\section{Conflicts of Interest}

The authors report no conflict of interest concerning the materials or methods used in this study or the findings specified in this paper. Meanwhile, this study was carried out with a 1688 AlM endoscopic system provided by Stryker.

\section{Ethics approval}

The study was approved by the appropriate institutional research ethics committee and certify that the study was performed in accordance with the ethical standards as laid down in the 1964 Declaration of Helsinki and its later amendments or comparable ethical standards. As the study is retrospective study, the informed consent was waived by ethics committee.

\section{Availability of data and material}

The manuscript has no mandatory deposition data and will not be deposited.

\section{Authors' Contribution}

$\mathrm{LMH}$, and LTK conceived and designed the study, and wrote the manuscript. They contributed equally.

\section{References}

1. Ben-Sira I, Riva CE (1975) Fluorescein diffusion in the human optic disc. Invest Ophthalmol 14:205211

2. Bischoff PM, Flower RW (1985) Ten years experience with choroidal angiography using indocyanine green dye: a new routine examination or an epilogue? Doc Ophthalmol 60:235-291. doi:10.1007/bf00157827

3. Patel KM, Bhanot P, Franklin B, Albino F, Nahabedian MY (2013) Use of intraoperative indocyaningreen angiography to minimize wound healing complications in abdominal wall reconstruction. $J$ Plast Surg Hand Surg 47:476-480. doi:10.3109/2000656x.2013.787085 
4. Sekijima M, Tojimbara T, Sato S, Nakamura M, Kawase T, Kai K, Urashima Y, Nakajima I, Fuchinoue S, Teraoka S (2004) An intraoperative fluorescent imaging system in organ transplantation. Transplant Proc 36:2188-2190. doi:10.1016/j.transproceed.2004.09.001

5. Soltesz EG, Laurence RG, De Grand AM, Cohn LH, Mihaljevic T, Frangioni JV (2007) Image-guided quantification of cardioplegia delivery during cardiac surgery. Heart Surg Forum 10:E381-386. doi:10.1532/hsf98.20071099

6. Raabe A, Beck J, Gerlach R, Zimmermann M, Seifert V (2003) Near-infrared indocyanine green video angiography: a new method for intraoperative assessment of vascular flow. Neurosurgery 52:132139, discussion 139. doi:10.1097/00006123-200301000-00017

7. Raabe A, Nakaji P, Beck J, Kim LJ, Hsu FP, Kamerman JD, Seifert V, Spetzler RF (2005) Prospective evaluation of surgical microscope-integrated intraoperative near-infrared indocyanine green videoangiography during aneurysm surgery. J Neurosurg 103:982-989. doi:10.3171/jns.2005.103.6.0982

8. de Oliveira JG, Beck J, Seifert V, Teixeira MJ, Raabe A (2007) Assessment of flow in perforating arteries during intracranial aneurysm surgery using intraoperative near-infrared indocyanine green videoangiography. Neurosurgery 61:63-72, discussion 72-63.

doi:10.1227/01.neu.0000289715.18297.08

9. Woitzik J, Horn P, Vajkoczy P, Schmiedek P (2005) Intraoperative control of extracranial-intracranial bypass patency by near-infrared indocyanine green videoangiography. J Neurosurg 102:692-698. doi:10.3171/jns.2005.102.4.0692

10. Uchino H, Nakamura T, Houkin K, Murata J, Saito H, Kuroda S (2013) Semiquantitative analysis of indocyanine green videoangiography for cortical perfusion assessment in superficial temporal artery to middle cerebral artery anastomosis. Acta Neurochir (Wien) 155:599-605. doi:10.1007/s00701-0121575-y

11. Kong D-S, Hong C-K, Hong SD, Nam D-H, Lee J-I, Seol HJ, Oh J, Kim DG, Kim YH (2019) Selection of endoscopic or transcranial surgery for tuberculum sellae meningiomas according to specific anatomical features: a retrospective multicenter analysis (KOSEN-002) \% J Journal of Neurosurgery JNS. 130:838. doi:10.3171/2017.11.Jns171337

12. Hong SD, Nam DH, Seol HJ, Choi NY, Kim HY, Chung SK, Dhong HJ (2015) Endoscopic binostril versus transnasal transseptal microscopic pituitary surgery: Sinonasal quality of life and olfactory function. Am J Rhinol Allergy 29:221-225. doi:10.2500/ajra.2015.29.4165

13. Hong SD, Nam D-H, Kong D-S, Kim HY, Chung S-K, Dhong H-J (2016) Endoscopic Modified Transseptal Transsphenoidal Approach for Maximal Preservation of Sinonasal Quality of Life and Olfaction. World Neurosurgery 87:162-169. doi10.1016/j.wneu.2015.12.050.

14. Terasawa M, Ishizawa T, Mise $Y$, Inoue $Y$, Ito H, Takahashi $Y$, Saiura A (2017) Applications of fusionfluorescence imaging using indocyanine green in laparoscopic hepatectomy. Surg Endosc 31:51115118. doi:10.1007/s00464-017-5576-z 
15. Ferroli P, Acerbi F, Albanese E, Tringali G, Broggi M, Franzini A, Broggi G (2011) Application of intraoperative indocyanine green angiography for CNS tumors: results on the first 100 cases. Acta Neurochir Suppl 109:251-257. doi:10.1007/978-3-211-99651-5_40

16. Kim EH, Cho JM, Chang JH, Kim SH, Lee KS (2011) Application of intraoperative indocyanine green videoangiography to brain tumor surgery. Acta Neurochir (Wien) 153:1487-1495, discussion 14941485. doi:10.1007/s00701-011-1046-x

17. Stummer W, Pichlmeier U, Meinel T, Wiestler OD, Zanella F, Reulen HJ (2006) Fluorescence-guided surgery with 5-aminolevulinic acid for resection of malignant glioma: a randomised controlled multicentre phase III trial. Lancet Oncol 7:392-401. doi:10.1016/s1470-2045(06)70665-9

18. Eljamel MS, Leese G, Moseley H (2009) Intraoperative optical identification of pituitary adenomas. J Neurooncol 92:417-421. doi:10.1007/s11060-009-9820-9

19. Marbacher S, Klinger E, Schwyzer L, Fischer I, Nevzati E, Diepers M, Roelcke U, Fathi AR, Coluccia D, Fandino J (2014) Use of fluorescence to guide resection or biopsy of primary brain tumors and brain metastases. Neurosurg Focus 36:E10. doi:10.3171/2013.12.focus13464

20. Micko A, Rapoport BI, Youngerman BE, Fong RP, Kosty J, Brunswick A, Shahrestani S, Zada G, Schwartz TH (2020) Limited utility of 5-ALA optical fluorescence in endoscopic endonasal skull base surgery: a multicenter retrospective study. Journal of Neurosurgery JNS:1. doi:10.3171/2020.5.jns201171

21. Litvack ZN, Zada G, Laws ER, Jr. (2012) Indocyanine green fluorescence endoscopy for visual differentiation of pituitary tumor from surrounding structures. J Neurosurg 116:935-941. doi:10.3171/2012.1.jns11601

22. Hide T, Yano S, Shinojima N, Kuratsu J (2015) Usefulness of the indocyanine green fluorescence endoscope in endonasal transsphenoidal surgery. J Neurosurg 122:1185-1192. doi:10.3171/2014.9.jns14599

23. Sandow N, Klene W, Elbelt U, Strasburger CJ, Vajkoczy P (2015) Intraoperative indocyanine green videoangiography for identification of pituitary adenomas using a microscopic transsphenoidal approach. Pituitary 18:613-620. doi:10.1007/s11102-014-0620-7

24. Chang SW, Donoho DA, Zada G (2019) Use of optical fluorescence agents during surgery for pituitary adenomas: current state of the field. J Neurooncol 141:585-593. doi:10.1007/s11060-018-03062-2

25. Verstegen MJT, Tummers Q, Schutte PJ, Pereira AM, van Furth WR, van de Velde CJH, Malessy MJA, Vahrmeijer AL (2016) Intraoperative Identification of a Normal Pituitary Gland and an Adenoma Using Near-Infrared Fluorescence Imaging and Low-Dose Indocyanine Green. Oper Neurosurg (Hagerstown) 12:260-268. doi:10.1227/neu.0000000000001328

26. Catapano G, Sgulò F, Laleva L, Columbano L, Dallan I, de Notaris M (2018) Multimodal use of indocyanine green endoscopy in neurosurgery: a single-center experience and review of the literature. Neurosurg Rev 41:985-998. doi:10.1007/s10143-017-0858-4

27. Inoue A, Ohnishi T, Kohno S, Nishida N, Nakamura Y, Ohtsuka Y, Matsumoto S, Ohue S (2015) Usefulness of an Image Fusion Model Using Three-Dimensional CT and MRI with Indocyanine Green 
Fluorescence Endoscopy as a Multimodal Assistant System in Endoscopic Transsphenoidal Surgery. Int J Endocrinol 2015:694273. doi:10.1155/2015/694273

28. Amano K, Aihara Y, Tsuzuki S, Okada Y, Kawamata T (2019) Application of indocyanine green fluorescence endoscopic system in transsphenoidal surgery for pituitary tumors. Acta Neurochir (Wien) 161:695-706. doi:10.1007/s00701-018-03778-0

29. Lee JYK, Cho SS, Zeh R, Pierce JT, Martinez-Lage M, Adappa ND, Palmer JN, Newman JG, Learned KO, White C, Kharlip J, Snyder P, Low PS, Singhal S, Grady MS (2018) Folate receptor overexpression can be visualized in real time during pituitary adenoma endoscopic transsphenoidal surgery with near-infrared imaging. J Neurosurg 129:390-403. doi:10.3171/2017.2.jns163191

30. Cho SS, Jeon J, Buch L, Nag S, Nasrallah M, Low PS, Grady MS, Singhal S, Lee JYK (2018) Intraoperative near-infrared imaging with receptor-specific versus passive delivery of fluorescent agents in pituitary adenomas. J Neurosurg 131:1974-1984. doi:10.3171/2018.7.jns181642

31. Teng CW, Huang V, Arguelles GR, Zhou C, Cho SS, Harmsen S, Lee JYK (2021) Applications of indocyanine green in brain tumor surgery: review of clinical evidence and emerging technologies. Neurosurg Focus 50:E4. doi:10.3171/2020.10.focus20782

32. Cheung TT, Ma KW, She WH, Dai WC, Tsang SHY, Chan ACY, Chok KSH, Lo CM (2018) Pure laparoscopic hepatectomy with augmented reality-assisted indocyanine green fluorescence versus open hepatectomy for hepatocellular carcinoma with liver cirrhosis: A propensity analysis at a single center. Asian J Endosc Surg 11:104-111. doi:10.1111/ases.12492

33. Takahashi H, Zaidi N, Berber E (2016) An initial report on the intraoperative use of indocyanine green fluorescence imaging in the surgical management of liver tumorss. J Surg Oncol 114:625-629. doi:10.1002/jso.24363

34. Shahein M, Montaser AS, Todeschini AB, Revuelta Barbero JM, Otto BA, Carrau RL, Prevedello DM (2018) Endoscopic Endonasal Resection of Tuberculum Sellae Meningioma with Utilization of Indocyanine Green. J Neurol Surg B Skull Base 79:S269-s270. doi:10.1055/s-0038-1625939

35. Turner HE, Nagy Z, Gatter KC, Esiri MM, Harris AL, Wass JA (2000) Angiogenesis in pituitary adenomas and the normal pituitary gland. J Clin Endocrinol Metab 85:1159-1162. doi:10.1210/jcem.85.3.6485

36. Dekkers OM, Pereira AM, Roelfsema F, Voormolen JH, Neelis KJ, Schroijen MA, Smit JW, Romijn JA (2006) Observation alone after transsphenoidal surgery for nonfunctioning pituitary macroadenoma. J Clin Endocrinol Metab 91:1796-1801. doi:10.1210/jc.2005-2552

37. Losa M, Mortini P, Barzaghi R, Ribotto P, Terreni MR, Marzoli SB, Pieralli S, Giovanelli M (2008) Early results of surgery in patients with nonfunctioning pituitary adenoma and analysis of the risk of tumor recurrence. J Neurosurg 108:525-532. doi:10.3171/jns/2008/108/3/0525

38. Brochier S, Galland F, Kujas M, Parker F, Gaillard S, Raftopoulos C, Young J, Alexopoulou O, Maiter D, Chanson $\mathrm{P}$ (2010) Factors predicting relapse of nonfunctioning pituitary macroadenomas after neurosurgery: a study of 142 patients. Eur J Endocrinol 163:193-200. doi:10.1530/eje-10-0255 
39. Lee MH, Lee JH, Seol HJ, Lee JI, Kim JH, Kong DS, Nam DH (2016) Clinical Concerns about Recurrence of Non-Functioning Pituitary Adenoma. Brain Tumor Res Treat 4:1-7. doi:10.14791/btrt.2016.4.1.1

40. Hwang J, Seol HJ, Nam DH, Lee JI, Lee MH, Kong DS (2016) Therapeutic Strategy for Cavernous Sinus-Invading Non-Functioning Pituitary Adenomas Based on the Modified Knosp Grading System. Brain Tumor Res Treat 4:63-69. doi:10.14791/btrt.2016.4.2.63

41. O'Sullivan EP, Woods C, Glynn N, Behan LA, Crowley R, O'Kelly P, Smith D, Thompson CJ, Agha A (2009) The natural history of surgically treated but radiotherapy-naïve nonfunctioning pituitary adenomas. Clin Endocrinol (Oxf) 71:709-714. doi:10.1111/j.1365-2265.2009.03583.x

42. Gras-Cabrerizo JR, Ademá-Alcover JM, Gras-Albert JR, Kolanczak K, Montserrat-Gili JR, MirapeixLucas R, Del Campo FS, Massegur-Solench H (2014) Anatomical and surgical study of the sphenopalatine artery branches. Eur Arch Otorhinolaryngol 271:1947-1951. doi:10.1007/s00405-0132825-1

\section{Tables}

Table 1 Case summaries.

\begin{tabular}{|llllll|}
\hline & Sex/age & Pathology & Size & Endoscopic EOR & ICG uptake \\
\hline Case 1 & F/49 & NFPA & $15 \mathrm{~mm}$ & GTR & +++ \\
\hline Case 2 & F/78 & NFPA & $25 \mathrm{~mm}$ & GTR & +++ \\
\hline Case 3 & M/28 & GH secreting PA & $25 \mathrm{~mm}$ & GTR & ++ \\
\hline Case 4 & M/44 & Pituitary apoplexy & $23 \mathrm{~mm}$ & GTR & - \\
\hline Case 5 & F/60 & Meningioma & $9 \mathrm{~mm}$ & GTR & - \\
\hline Case 6 & F/46 & Meningioma & $22 \mathrm{~mm}$ & STR & - \\
\hline
\end{tabular}

F: female, M: male, NFPA: non-functioning pituitary adenoma, GH: growth hormone, EOR: extent of resection, ICG: indocyanine green, GTR: gross total resection, NTR: subtotal resection.

\section{Figures}




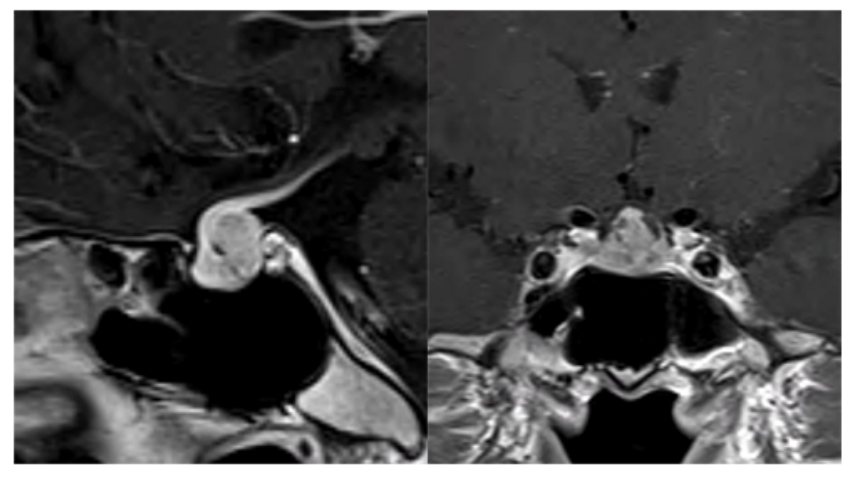

A

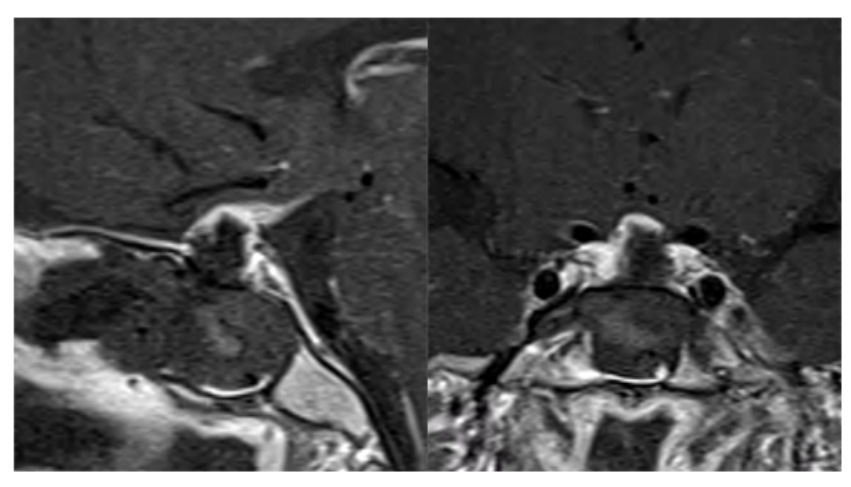

B

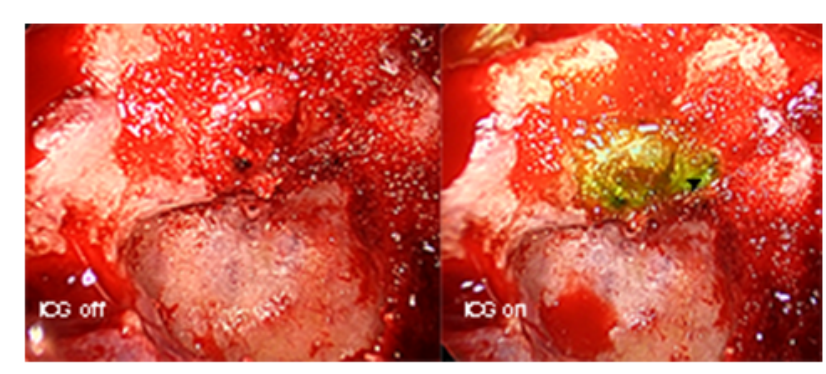

C

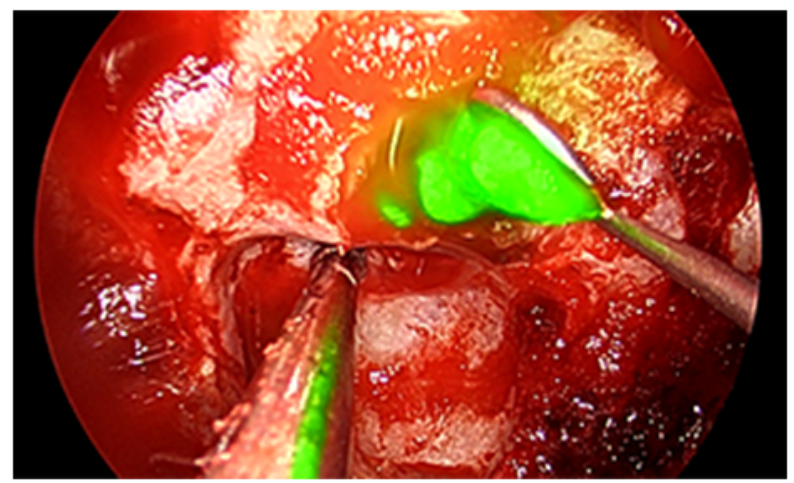

D

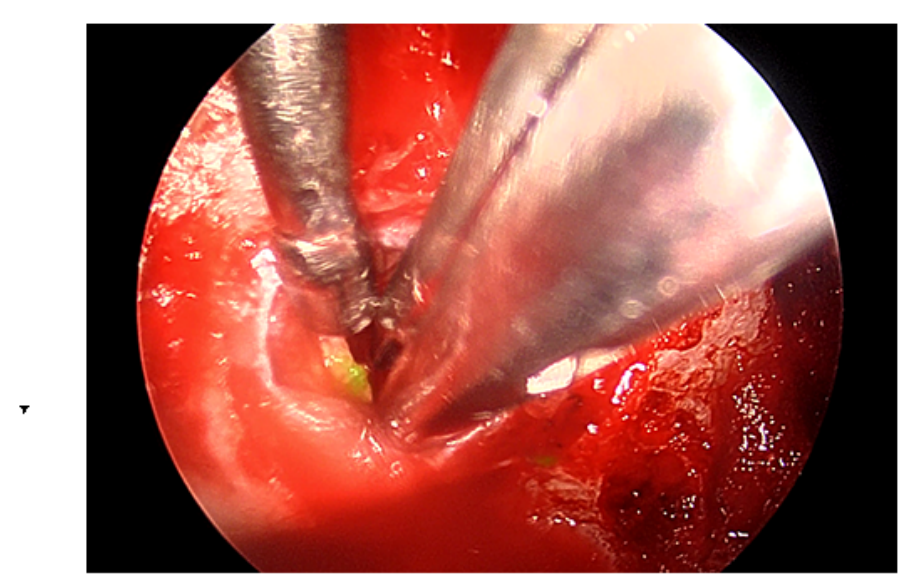

$\mathrm{E}$

\section{Figure 1}

Case 1: Non-functioning pituitary adenoma. A) Pre-operative MRI, B) post-operative MRI, C) tumor visualization without ICG and with ICG, D) tumor resection with ring curette, E) residual tumor with ICG uptake. $\varangle$ indicates the border of the tumor and normal areas based on the neuro-navigation system. * indicates the residual tumor. 


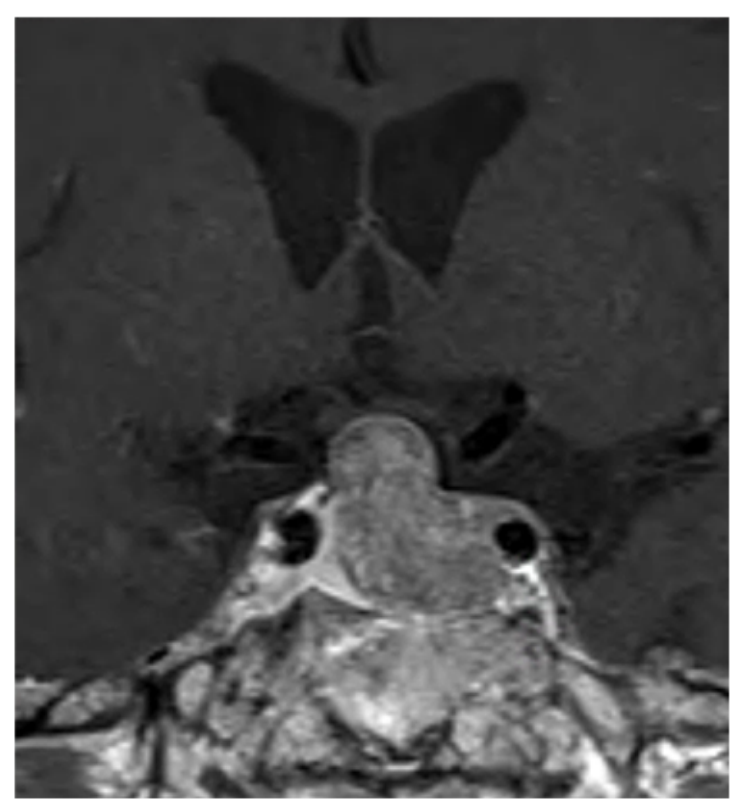

A

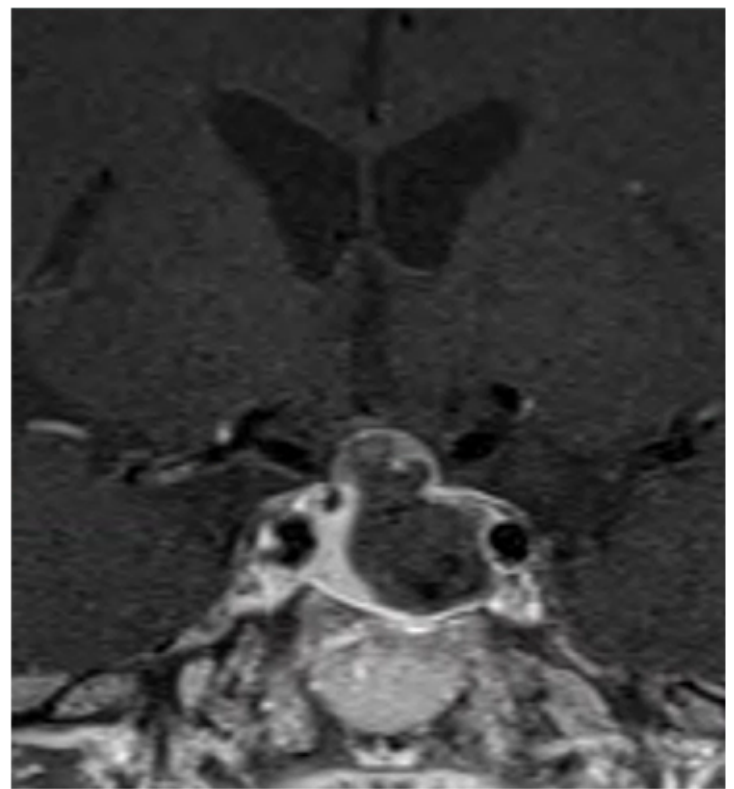

B

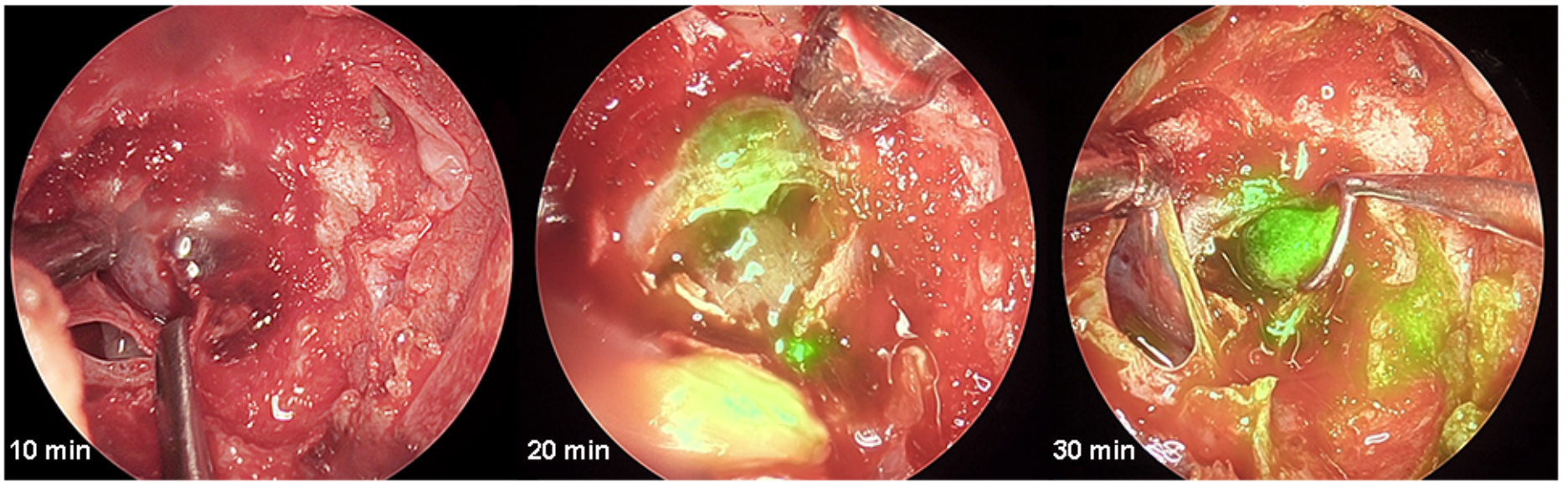

C

\section{Figure 2}

Case 2: Non-functioning pituitary adenoma. A) Pre-operative MRI, B) post-operative MRI, with time lapse, C) 10 minutes after ICG injection, D) after 20 minutes, E) after 30 minutes. 


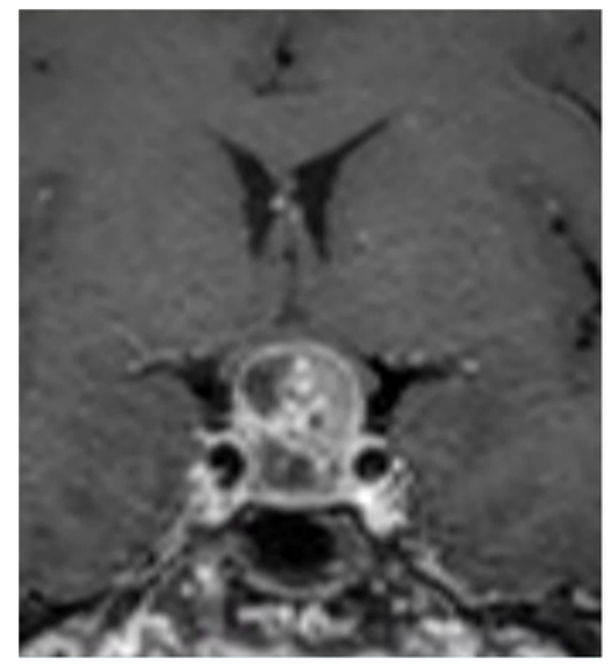

A

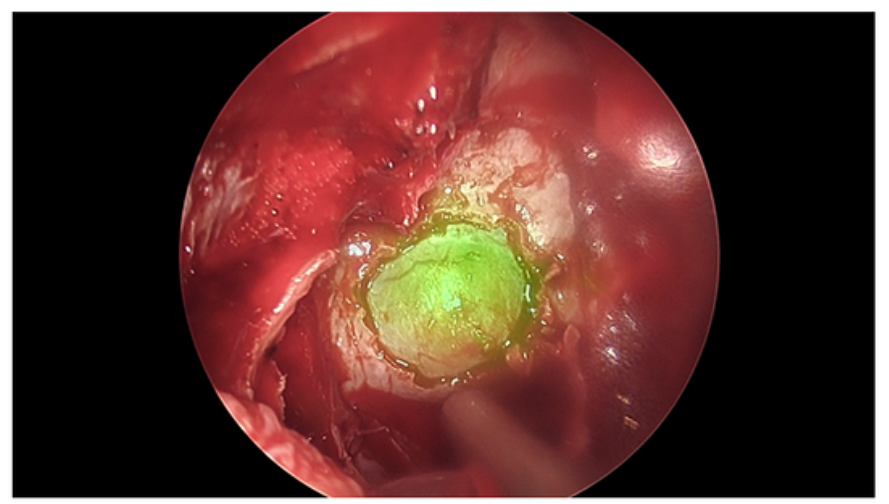

C

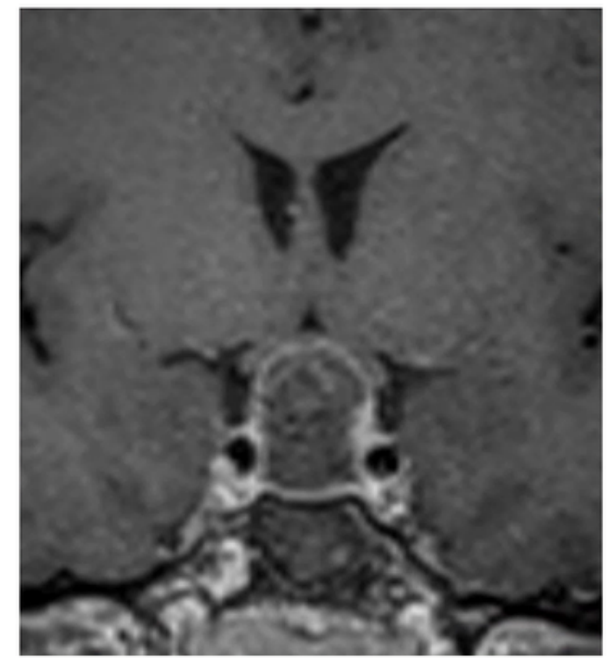

B

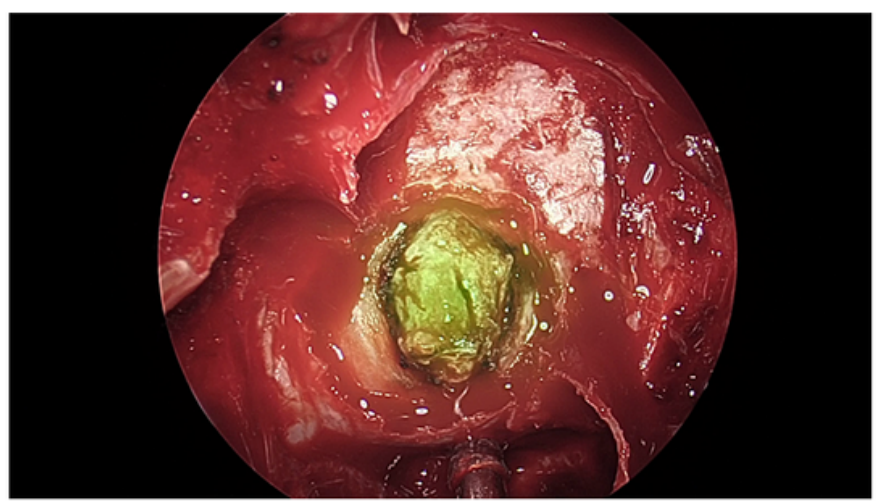

D

\section{Figure 3}

Case 3: Growth hormone secreting pituitary adenoma. A) Pre-operative MRI, B) post-operative MRI, tumor visualization with ICG $\mathrm{C}$ ) before, and $\mathrm{D}$ ) after opening the dura. 

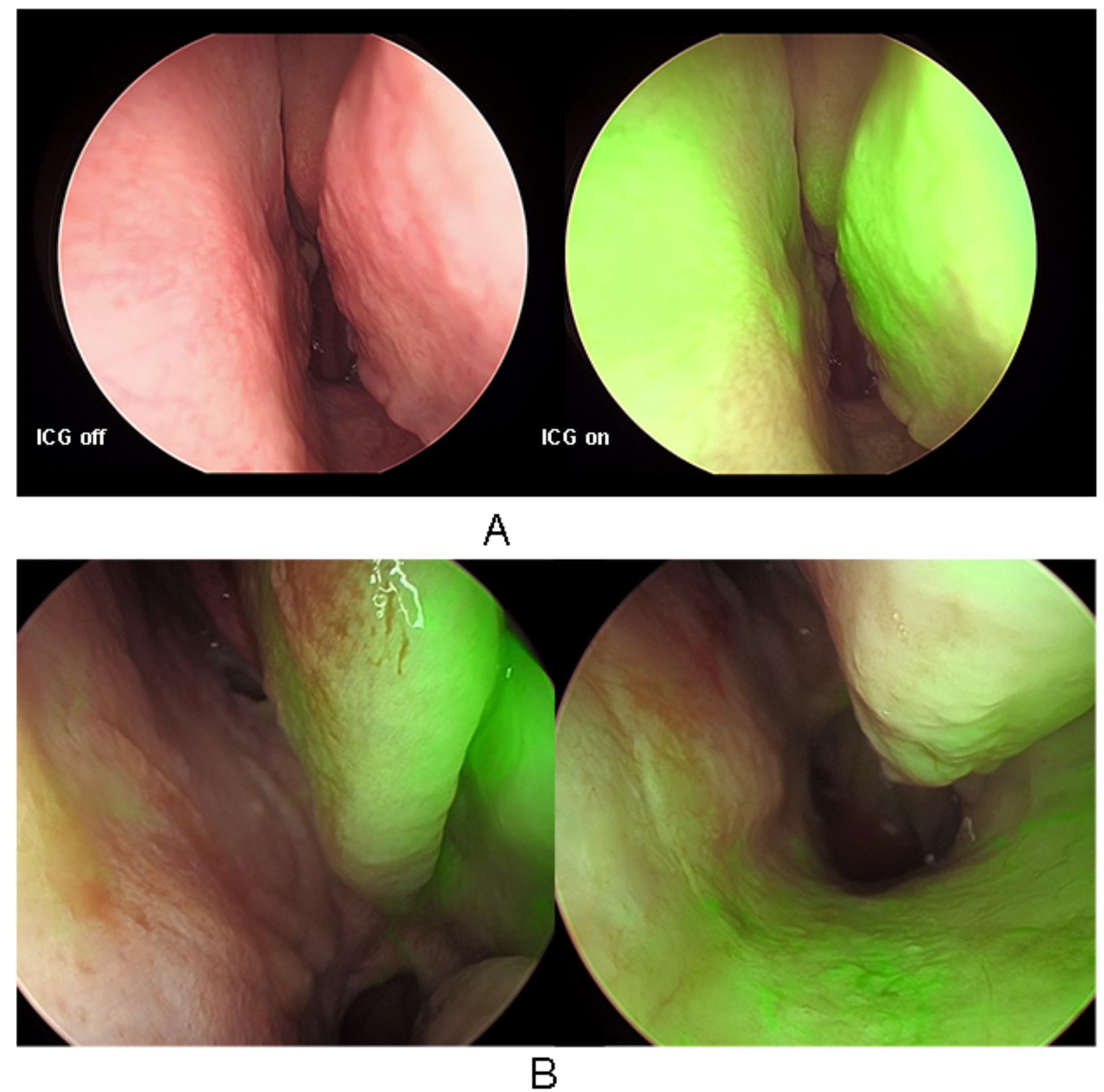

\section{Figure 4}

Nasoseptal flap. A) Healthy septal mucosa, under white light window (left), and under ICG window (right) B) unhealthy septal mucosa, previously underwent septoplasty, low uptake of septal mucosa (left), and high uptake of floor mucosa

\section{Supplementary Files}

This is a list of supplementary files associated with this preprint. Click to download.

- Video1.mp4 